\title{
Overclaiming responsibility in fictitious countries: Unpacking the role of availability in support theory predictions of overclaiming
}

\author{
Morgan Quinn Ross ${ }^{1} \cdot$ Olivia A. Sterling-Maisel ${ }^{2} \cdot$ Olivia Tracy $^{3} \cdot$ Adam L. Putnam $^{3}$ \\ Published online: 19 June 2020 \\ (C) The Psychonomic Society, Inc. 2020
}

\begin{abstract}
Prior research has demonstrated that Americans massively overestimate how much their home state has contributed to US history. Why does such collective overclaiming occur? We argue that although self-serving biases undoubtedly influence overclaiming, non-motivated factors, such as a failure to consider the contributions of other states, also play a large role in overclaiming effects. In the current studies, subjects read descriptions of territories within a fictitious country and evaluated how much a territory within that country contributed to its history. Experiment 1 showed that overclaiming of responsibility increased as more territories were added to the country. Experiments 2 and 3 showed that requiring subjects to explicitly consider all territories reduced estimations of responsibility. Experiment 4 showed that people provided higher ratings of responsibility when more details were provided about the territory. Finally, Experiment 5 showed that retrieval fluency did not affect overclaiming. We conclude that support theory - based on the availability of content - provides a strong explanation for why the collective overclaiming of responsibility occurs, with both theoretical and practical implications.
\end{abstract}

Keywords Judgment $\cdot$ Memory $\cdot$ Reasoning $\cdot$ Collective memory $\cdot$ Overclaiming $\cdot$ Support theory

\section{Introduction}

The tendency to overclaim responsibility for shared tasks is a robust and reliable finding in social psychology. Spouses overclaim the amount of house-work they complete (M. Ross \& Sicoly, 1979), basketball players overclaim responsibility on the court (Savitsky, Van Boven, Epley, \& Wight, 2005), and academics even overclaim their contributions to journal articles (Schroeder, Caruso, \& Epley, 2016; for reviews see Gilovich, Kruger, \& Savitsky, 1999; Leary \& Forsyth, 1987). Recent research has also shown that people overclaim responsibility for their groups. Americans, on average, believe that their home states have directly contributed

Electronic supplementary material The online version of this article (https://doi.org/10.3758/s13421-020-01059-9) contains supplementary material, which is available to authorized users.

Adam L. Putnam

adam.putnam@furman.edu

1 School of Communication, The Ohio State University, Columbus, OH, USA

2 Department of Psychology, Carleton College, Northfield, MN, USA

3 Department of Psychology, Furman University, 3300 Poinsett Highway, Greenville, SC 29613, USA
$18 \%$ of US history, leading to a total contribution of just over 900\% (Putnam, M. Q. Ross, Soter, \& Roediger, 2018). Such collective overclaiming is not solely American: people from a myriad of countries also overclaim responsibility for world history (Zaromb et al., 2018).

Why does the overclaiming of responsibility occur? Any phenomenon as robust as overclaiming of responsibility is likely to have multiple independent mechanisms (Schroeder et al., 2016). Our current goal is to identify and examine some specific mechanisms that underlie collective overclaiming.

\section{Explanations of overclaiming}

In previous work we suggested three classes of explanations for collective overclaiming (Putnam et al., 2018). A first class revolves around ego-protection and other self-serving biases: people want to see themselves and their groups in a positive light (e.g., Taylor \& Brown, 1988). Individuals overclaim less when evaluating negative outcomes compared to positive outcomes, and people who identify more strongly with their country are more likely to overclaim their country's contributions to world history (Kruger \& Gilovich, 1999; M. Ross \& Sicoly, 1979; Zaromb et al., 2018). Given a host of other social psychological findings - such as above-average effects 
- self-serving biases likely contribute to overclaiming (e.g., Klar, 2002).

Other explanations of overclaiming are non-motivated or cognitive in nature. One frequently proposed mechanism is the availability heuristic, which suggests that judgments are shaped by the information that is brought to mind (the content of retrieval) and the ease of bringing that information to mind (the fluency of retrieval; Tversky \& Kahneman, 1973; Schwarz et al., 1991). A spouse may remember taking out the trash but not their partner doing laundry (M. Ross \& Sicoly, 1979). In collective contexts, people have more knowledge about themselves and their group - and more fluent access to that knowledge - than they do about other people or groups. A New Englander might remember the Boston Tea Party instead of the Alamo, and even if they remember the Alamo, retrieval fluency will be lower. Thus, when evaluating contributions to a shared outcome, people make their judgments based on what comes to mind and how easily it comes to mind.

A final class of mechanisms is that people are generally poor intuitive statisticians. One helpful framework here is support theory (Tversky \& Koehler, 1994). Support theory is a formal model that describes how people estimate probabilities for events. The premise is that people make judgments based on descriptions of events, rather than the events themselves. For example, when asked to evaluate the probability that either (a) 1,000 people will die in a natural disaster, or (b) that 1,000 people will die in an earthquake, tornado, or other natural disaster, people assign a higher probability to the second category. The specific examples of earthquakes and tornados - "unpacking" the larger category of natural disasters into specific events - makes those instances salient and encourages retrieval of other relevant information (Rottenstreich \& Tversky, 1997).

Fruitful interplay emerges between these latter two classes of mechanisms. Support theory integrates a number of cognitive biases. It proposes that people's probability judgments are based on the degree of support for the target or focal hypothesis (i.e., the question or statement being evaluated) compared to the degree of support for alternative hypotheses. Because support is based on descriptions, support for a hypothesis can come from data or be "mediated by judgmental heuristics, such as representativeness, availability, or anchoring and adjustment" (Tversky \& Koehler, 1994, p. 549). Furthermore, support theory also integrates ideas related to focalism, which suggests that people overweigh focal hypotheses and fail to consider alternative hypotheses (Klar, 2002; Windschitl, Kruger, \& Simms, 2003). Overall, in the context of overclaiming, support theory and its cognitive mechanisms suggest that people base decisions largely on their own contributions (which are salient) instead of considering the contributions of others.

\section{The current study}

The current study has three main goals. The first is to demonstrate that collective overclaiming can occur without selfserving biases. These explanations are appealing, yet fail to account for some overclaiming findings, such as the finding that overclaiming increases with group size (Schroeder et al., 2016). While other research suggests that overclaiming can occur without ego-protection mechanisms (Kruger \& Gilovich, 1999; M. Ross \& Sicoly, 1979), such studies often rely on having people claim responsibility for negative outcomes; If driven only by ego-protection, people should underclaim responsibility for negatives outcomes, yet people continue to overclaim responsibility (if to a lesser degree), perhaps to avoid the guilt of shirking responsibility. Thus, even in these scenarios, overclaiming may be a self-serving mechanism. To address this issue, in our study people rated how territories in a fictitious country contributed to the country's history. This novel paradigm may not be wholly realistic, but this bug is also a key feature: it allows us to avoid self-serving biases.

The second goal was to examine predictions from support theory as explanations for collective overclaiming. A key component of support theory - implicit subadditivity - relies on the availability heuristic (Brenner, Koehler, \& Rottenstreich, 2002). When a proposition is unpacked, knowledge of that proposition becomes more available. As a result, the perceived likelihood or importance of the proposition increases. In other words, when the proposition is only considered implicitly, its resulting likelihood is sub-additive (i.e., less than the summed likelihood of its components). One issue in the context of overclaiming, however, is whether the increased support comes from the contents of unpacking or the fluency of processing the unpacked content (Schwarz \& Vaughn, 2002). Unpacking a proposition not only increases the amount of content available about the proposition, but also the fluency of such information, leaving the precise causal mechanism by which support impacts overclaiming via availability unknown. Therefore, we investigated the role of availability in support theory with regards to overclaiming responsibility. Our novel paradigm facilitated this investigation, as content and fluency of information are easily manipulated in fictitious scenarios.

Finally, our third goal was to model collective overclaiming. In contrast to the vast literature on overclaiming in small groups - where individuals rate their personal contribution to a group - in collective overclaiming people rate the contribution of a group to a larger whole. It is important to establish whether the same principles guide collective assessments of responsibility, as people's intuitive judgments about groups are often qualitatively different to their intuitive judgments about individuals (McConnell, Sherman, \& Hamilton, 1994). For example, while individuals know their own 
actions, as a group member they may have more or less information about the group's actions (especially if the group's actions are from the distant past).

We conducted five studies. Experiments 1, 2, and 3 examined implicit subadditivity and unpacking by having subjects rate the contribution of a territory to a fictitious country and varying the number of other territories in the country or whether the territory was rated in isolation or alongside other territories. Experiments 4 and 5 focused on the availability heuristic, providing subjects with minimal or more detailed descriptions of one of the territories and forcing subjects to recall more or less information to test whether content or fluency drives overclaiming. In sum, we evaluated the robustness of support theory and the role of availability in accounting for overclaiming.

\section{Experiment 1}

Experiment 1 tested a specific aspect of support theory: implicit subadditivity. Implicit subadditivity suggests that a category rating will be less than or equal to the sum of ratings for individual components within that category (Tversky \& Koehler, 1994). Prior work shows that overclaiming increases as group size increases, presumably because people rate the sum of others in their group rather than considering each individual (Schroeder et al., 2016).

In Experiment 1 subjects read a description of a territory (Adivigan) in a fictitious country (Oloram). Adivigan was described as being one of 5, 20 , or 50 territories within Oloram. Subjects then rated how much Adivigan contributed to the history of Oloram. We predicted that people would overclaim responsibility compared to a mathematically "correct" response and that overclaiming would increase when there were more territories. Experiments 1, 3, 4, and 5 were preregistered on the Open Science Framework where we identified our sample size goal, data exclusion rules, hypotheses, and analysis plan (see OSF.IO/X7G8B for links to each preregistration and other project materials). We report all variables collected here or in the Supplemental Online Materials.

\section{Method}

Subjects We recruited 302 subjects (130 males, 171 females, one other; age: $M$ (mean) $=39.19$ years, $S E$ (standard error) $=$ 0.78) through Amazon Mechanical Turk who had not participated in other overclaiming research done in our lab. We preregistered two exclusion criteria for all studies: missing answers to critical questions or not speaking English fluently. Experiments 3 and 5 had additional exclusion criteria outlined later. For Experiment 1, no subjects met our exclusion criteria, so all subjects who completed the survey were included in our analyses. All subjects were only able to participate in one of the studies in this paper.

Materials and procedure After answering demographic questions, subjects read about a fictitious country and estimated how much a territory in that country had contributed to the overall history of the country. This critical question was the key question from Putnam et al. (2018) adapted for a fictitious country. Subjects were randomly assigned to one of three conditions: 5-Territory $(n=100), 20$-Territory $(n=102)$, or 50-Territory $(n=100)$. They then saw a brief description of Adivigan along with the critical question:

"Oloram is a country that has existed for over a hundred years. Within Oloram there are [5/20/50] territories, each of which has its own government that works in conjunction with the national government. Adivigan is one of the $[5 / 20 / 50]$ territories in Oloram.

In terms of percentage, what do you think was Adivigan's contribution to the history of Oloram? In other words, how responsible was Adivigan for the historical developments in Oloram? Keep in mind that there are $[5 / 20 / 50]$ territories and that the total contribution for all territories has to equal $100 \%$."

Subjects saw the description of Adivigan and the critical question, and after $15 \mathrm{~s}$ (to ensure that subjects read the full paragraph) a slider appeared, anchored with $0 \%$ on the left and $100 \%$ on the right. Subjects dragged the slider to identify how much they thought Adivigan had contributed to Oloram's history. Subjects then wrote a short explanation of their response. ${ }^{1}$

\section{Results}

In all of our analyses we used .05 to indicate statistical significance. We used Welch two-sample $t$-tests, which adjust for unequal variance between groups, and Cohen's $d$ to measure effect size. We preregistered our decision to use one-tailed tests for directional predictions in Experiments $1-4 .^{2}$ Our data were often non-normal, as indicated by visual inspection of the distributions and the results of Shapiro-Wilk tests, so we also used two-tailed nonparametric Kruskal-Wallis rank sum tests and Wilcoxon rank sum tests.

\footnotetext{
${ }^{1}$ We gathered these responses to help guide future research, but did not conduct any analyses with them.

${ }^{2}$ We justified the use of one-tailed tests as follows. First, while using onetailed tests increases the chance of finding an effect in a certain direction, it also prevents the possibility of finding significant effects in the opposite direction. Second, in light of preregistration, the use of one-tailed tests can be clearly shown to be a priori due to our theoretical predictions. We also ran all analyses with two-tailed tests and found that all but one significant finding (in E2B) remained significant.
} 
Average estimated contribution Across all conditions, subjects estimated, on average, that Adivigan contributed 17\% $(\operatorname{Mdn}$ (median $)=10 \% ; 95 \%$ confidence interval $(\mathrm{CI})[15 \%$, $19 \%]$ ) to the history of Oloram. As predicted, the responses varied depending on the number of territories in Oloram, $F(2$, 299) $=9.39, p<.001$. One-tailed $t$-tests revealed that the mean estimate for the 5-Territory condition $(M=23 \%$; $M d n=20 \%$; $95 \%$ CI $[21 \%, 26 \%])$ was higher than the 20-Territory condition $(M=16 \% ; \mathrm{Mdn}=5 \% ; 95 \%$ CI $[11 \%, 21 \%]), t(146.37)=2.68, p$ $=.004, d=0.37$, and the 50-Territory condition $(M=12 \%$; $\mathrm{Mdn}$ $=5 \% ; 95 \%$ CI $[9 \%, 16 \%]), t(172.19)=5.33, p<.001, d=0.75$, but that the difference between the 20-Territory and 50-Territory condition was not significant, $t(184.54)=1.38, p=.085, d=$ 0.19 . A non-parametric Kruskal-Wallis rank sum test revealed a significant difference for the responses as a function of the number of territories, $H(2)=89.29, p<.001$. Wilcoxon rank sum tests indicated that the 5-Territory condition led to significantly higher responses than the 20-Territory condition, $T=8302.5, p<$ .001 , and that, unlike above, the 20-Territory condition led to significantly higher responses than the 50-Territory condition, $T$ $=6303.5, p=.003$. Altogether, subjects logically provided higher estimates of Adivigan's importance when Oloram was described as having fewer territories; each territory would make more important contributions with fewer other territories present.

Total implied contribution Because the number of territories varied across conditions, however, we cannot directly compare the mean responses in each condition. A contribution rating of $10 \%$ would represent underclaiming in the 5Territory condition but overclaiming in the 50-Territory condition. Thus, we also examined total implied contribution (TIC; Schroeder et al., 2016). TIC was calculated by multiplying each subject's rating by the number of territories in their condition, which provided an estimate of the total historical contribution to Oloram if each territory were as important as Adivigan. For example, if a subject provided a rating of $40 \%$ in the 5-Territory condition, the TIC would be $200 \%$. Logically, TIC should equal $100 \%$.

Figure 1 shows the TIC for each condition. The TIC in all conditions was significantly higher than $100 \%$ : 5-Territory, $t(99)=2.77, p=.007 ; 20$-Territory, $t(101)=4.67, p<.001$; 50-Territory, $t(99)=5.74, p<.001$. Wilcoxon signed rank tests yielded a similar conclusion: 5-Territory, $T=297.5, p=$ $.002 ;$ 20-Territory, $T=764.5, p<.001 ; 50$-Territory, $T=$ $1653, p<.001$. Thus, in all conditions subjects showed higher TIC than would be expected from a mathematical approach, indicating overclaiming of responsibility. The CIs in Fig. 1 vary widely, as they were calculated after imputing the TIC, but the $95 \%$ CIs for the original mean values (see above) show consistent variability across conditions.

More importantly, the number of territories influenced the ratings, $F(2,299)=17.90, p<.001$. The TIC for the 5 Territory condition was lower than the 20-Territory,

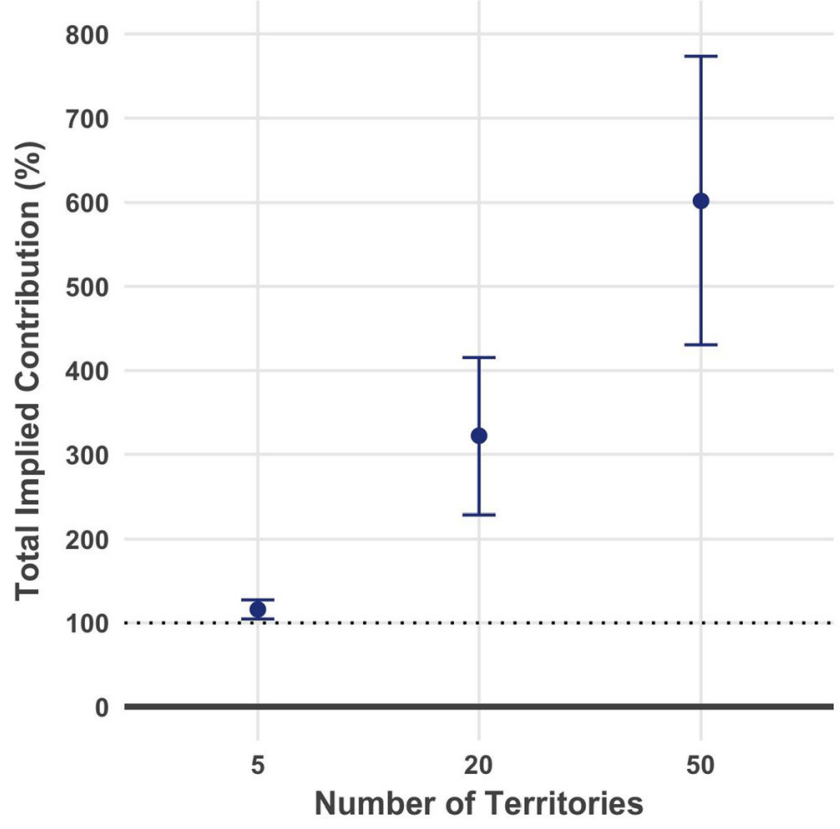

Fig. 1 Total implied contribution (TIC) in Experiment 1 as a function of how many territories were in Oloram. TIC was calculated by multiplying each subject's response by the number of territories in Oloram. The dotted line represents $100 \%$, or the logically correct answer. Error bars represent $95 \%$ confidence intervals

$t(104.01)=4.30, p<.001, d=0.60$, which in turn was lower than the 50-Territory condition, $t(153.25)=2.81, p=.006, d=$ 0.40 . Non-parametric analyses confirmed these results. The TIC varied across conditions, $H(2)=47.97, p<.001$, and the TIC was lower in the 5-Territory condition than in the 20-Territory condition, $T=3954.5, p<.001$, which in turn was lower than in the 50-Territory condition, $T=3731, p<$ .001 . As predicted, overclaiming increased as more territories were added to Oloram.

Exploratory analysis To explore the possibility that people treated the problem like a math problem, we conducted an exploratory analysis to examine the percentage of people who gave a mathematically correct answer as a function of condition - that is, what percentage of people in the 5Territory, 20-Territory, and 50-Territory conditions said $20 \%, 5 \%$, and $2 \%$, respectively. Critically, this percentage changed across conditions: $74 \%$ in the 5-Territory condition, $62 \%$ in the 20-Territory condition, and $43 \%$ in the 50 Territory condition, $\chi^{2}(2,302)=20.26, p<.001$. Subjects were more likely to provide a mathematically correct answer when Oloram had fewer territories.

\section{Discussion}

In Experiment 1 subjects overclaimed responsibility for Adivigan. Because Adivigan is a fictitious territory, subjects had no prior affiliation with Adivigan, which suggests that 
overclaiming was not driven exclusively by motivated (i.e., self-serving) factors. More importantly, overclaiming increased as Oloram gained territories, confirming our prediction from support theory. This outcome likely occurred because people considered the contributions of the target territory, but lumped the other territories together (i.e., didn't unpack the alternative hypothesis), resulting in an over-emphasis on the focal hypothesis; as more territories are included in the "other" group, the magnitude of the error increases. This study conceptually replicates the findings of Schroeder et al. (2016) and extends it to the new context of collective overclaiming.

One alternative explanation, as suggested by our exploratory analysis, is that subjects may have been more or less likely to use a mathematical approach in making a rating, as the mathematical approach was easier in some conditions than others. Thus, in Experiment 2 we kept the number of territories constant. More importantly, Experiment 2 examined another crucial aspect of support theory - unpacking - and whether judgments of responsibility can be reduced by forcing subjects to explicitly consider the other territories in Oloram.

\section{Experiment 2}

Prior work has shown that drawing attention to the contributions of other group members reduces overclaiming (Caruso, Epley, \& Bazerman, 2006; M. Ross \& Sicoly, 1979, Experiment 5; Savitsky et al., 2005). Consistent with support theory, providing more support for alternative hypotheses reduces support for the central hypothesis. In Experiment 2 we forced subjects to explicitly consider all of the territories in Oloram. We adapted an approach used in examining collective memories for World War II (Roediger et al., 2019). Subjects rated either a single territory in Oloram or rated five territories at the same time. We predicted that rating isolated territories would lead to higher estimates of the target territory than rating all of the territories at once. This latter condition the unpacked condition - required subjects to explicitly evaluate each of the territories rather than evaluate them as a group (Savitsky et al., 2005). Experiment 2 was conducted twice; in Experiment 2A subject responses in the unpacked conditions were forced to sum to $100 \%$, whereas in Experiment 2B they were not.

\section{Method}

Subjects In Experiment 2A we recruited 282 Amazon Turk Workers ( 135 males, 147 females; age: $M=35.13$ years, $S E=$ 0.73 ). Three additional subjects completed the experiment, but did not speak English fluently, so we omitted their data from all analyses. Similarly, in Experiment 2B we recruited 287 Amazon Turk Workers (147 males, 140 females; age: $M$ $=35.65$ years, $S E=0.66)$. Sixteen additional subjects completed Experiment 2B, but one or more responses to the critical question were missing so we omitted the data from those subjects from all analyses. ${ }^{3}$

Materials and procedure Experiment 2 used a similar procedure to Experiment 1. We created descriptions of four new territories within Oloram in addition to Adivigan: Rutroka, New Ceyer, Brodiyan, and Lanemi (see Appendix). The descriptions for each territory had similar lengths and types of information (e.g., major industries, geographical features) and were written so the territories seemed equally important to Oloram.

Subjects were randomly assigned to either the unpacked condition ( $n=47,51$ for E2A and E2B respectively), where they rated all of the territories at once, or one of the isolated conditions, where they rated only one of the territories (Rutroka, $n=46,48$; New Ceyer, $n=48,45$; Brodiyan, $n=$ 47, 45; Lanemi, $n=49,51$; Adivigan, $n=45$, 47). Subjects in the isolated condition read the description of one territory and then answered the critical question. In the unpacked condition subjects saw the descriptions of all five territories at once. They read the descriptions of each territory and (after at least $30 \mathrm{~s}$ ) were asked to assign a rating between $0 \%$ and $100 \%$ for each territory by typing a number into a box. In Experiment 2A subject responses in the unpacked conditions were forced to sum to $100 \%$, whereas in Experiment 2B they were not.

\section{Results}

Figures 2 and 3 show the average rating for the five different territories in the isolated and unpacked conditions for Experiments 2A and 2B.

Experiment 2A As shown in Fig. 2, subjects in the isolated conditions gave higher estimates of responsibility $(M=39 \%$; $\mathrm{Mdn}=30 \% ; 95 \% \mathrm{CI}=[35 \%, 42 \%])$ compared to subjects in the unpacked condition $(M=20 \%$; $\mathrm{Mdn}=20 \% ; 95 \% \mathrm{CI}=$ $[19 \%, 21 \%])$. Summing the average response for each territory in the isolated conditions led to a total contribution of $100 \%$ (unsurprising, as the responses were required to sum to $100 \%$ ), whereas summing the average response in the unpacked condition led to a total response of $194 \%$.

All five territories showed that the isolated condition led to higher estimates than the unpacked condition: Rutroka, $t(72.34)=5.24 p<.001, d=1.09$; New Ceyer, $t(50.88)=$ $5.49, p<.001, d=1.12$; Brodiyan, $t(50.72)=3.64, p<$ $.001, d=0.75$; Lanemi, $t(59.83)=4.53, p<.001, d=0.91$; Adivigan, $t(51.94)=5.00, p<.001, d=1.06$. Wilcoxon rank sum tests yielded a similar conclusion: Rutroka, $T=403.50, p$ $<.001$, New Ceyer, $T=455.50, p<.001$, Brodiyan, $T=$ 672.50, $p<.001$, Lanemi, $T=525.00, p<.001$, Adivigan, $T$

\footnotetext{
${ }^{3}$ The results did not change if we included all subjects.
} 


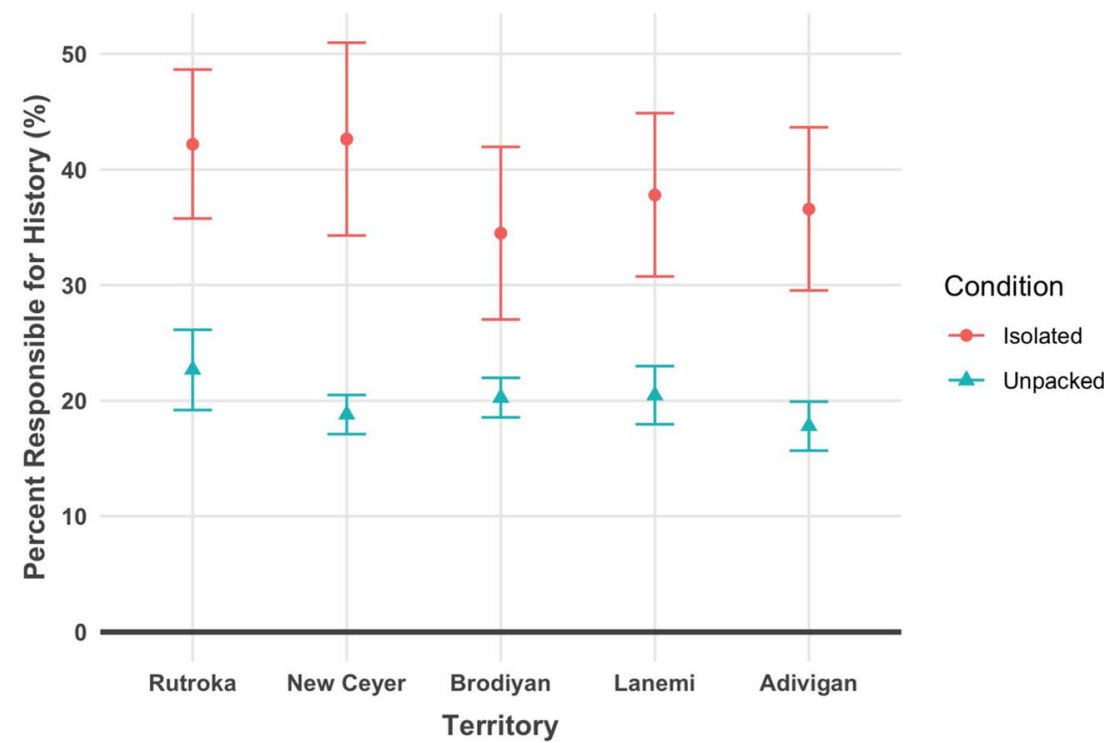

Fig. 2 Percentage estimate of how much each territory contributed to the history of Oloram in Experiment 2A. Subjects in the isolated condition rated a single territory (so the five points represent five different groups of

subjects); subjects in the unpacked condition rated all five territories (so the five points represent one group of subjects). Error bars represent $95 \%$ confidence intervals

$=410.50, p<.001$. Seeing all of the territories together led to lower estimates of responsibility than rating a single territory.

As an exploratory analysis we examined the number of subjects who appeared to respect additivity. Because the subjects in the unpacked condition were required to provide answers to equal $100 \%$, all of them provided an additive response. In contrast, only $29 \%$ of subjects in the isolated condition provided answers of $20 \%$, which would sum to $100 \%$ when applied across all territories (similar to our TIC measure from Experiment 1).

Experiment 2B Figure 3 shows that subjects in the isolated conditions $(M=38 \%$; $\mathrm{Mdn}=30 \% ; 95 \% \mathrm{CI}=[35 \%, 41 \%])$ provided higher ratings than subjects in the unpacked condition $(M=23 \% ; \mathrm{Mdn}=20 \% ; 95 \% \mathrm{CI}=[21 \%, 25 \%])$. Furthermore, summing the average response for each territory in the isolated condition led to a total contribution of $188 \%$, whereas summing the average response in the unpacked condition led to a total response of $114 \%$.

The ratings in the isolated condition were higher than the ratings in the unpacked condition for all five territories:

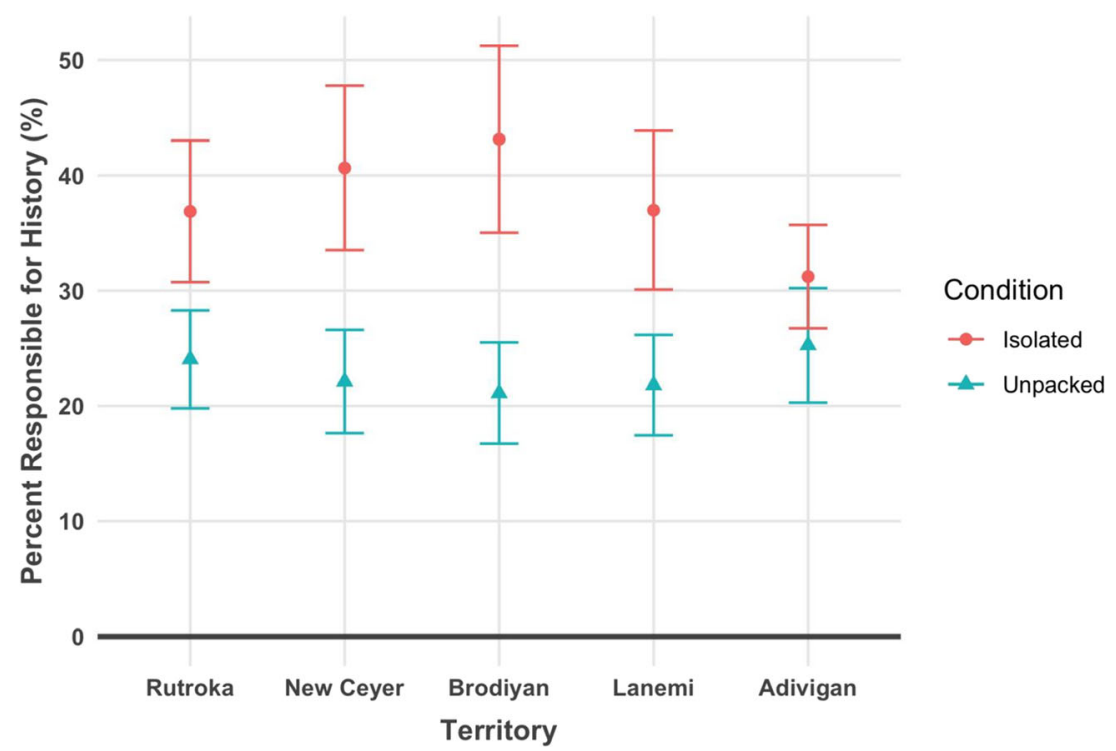

Fig. 3 Percentage estimate of how much each territory contributed to the history of Oloram in Experiment 2B. Subjects in the isolated condition rated a single territory (so the five circle points represent five different groups of subjects); subjects in the unpacked condition rated all five territories (so the five triangle points represent one group of subjects). Error bars represent $95 \%$ confidence intervals 
Rutroka, $t(84.34)=3.37, p<.001, d=0.68$; New Ceyer, $t(75.17)=4.32, p<.001, d=0.90$; Brodiyan, $t(68.32)=$ $4.68, p<.001, d=1.00$; Lanemi, $t(84.34)=3.65, p<.001$, $d=0.72$; Adivigan, $t(95.69)=1.75, p=.042, d=0.35 .^{4}$ Wilcoxon rank sum tests yielded a similar conclusion: Rutroka, $T=695.5, p<.001$, New Ceyer, $T=503.5, p<$ .001 , Brodiyan, $T=559, p<.001$, Lanemi, $T=689, p<$ .001 , Adivigan, $T=813.5, p=.004$, indicating that the isolated condition led to consistently higher ratings.

As an exploratory analysis we examined the number of subjects who respected additivity. While $84 \%$ of subjects in the unpacked condition provided ratings that totaled to $100 \%$, only $30 \%$ percent of subjects in the isolated group provided a rating (i.e., $20 \%$ ) that would total $100 \%$ if applied to all territories. Overall, subjects in the unpacked condition were fairly consistent in respecting additivity but subjects in the isolated condition did not seem to consider additivity.

\section{Discussion}

The results of Experiment 2 were clear: rating an individual territory led to higher estimates of each territory's contributions compared to rating all of the territories at once. This finding replicates prior research in that requiring subjects to explicitly unpack the contributions of non-focal entities reduces overclaiming (Caruso et al., 2006; Savitsky et al., 2005). The current results, however, show that this effect occurs without ego-protection mechanisms and in a collective overclaiming context. Figures 2 and 3 may suggest that the difference between the isolated and unpacked conditions was larger in E2A than in E2B, but an exploratory analysis comparing the two experiments (reported in the SOM) did not reveal any significant differences between experiments.

This pattern of results is consistent with support theory rating all of the territories simultaneously is equivalent to unpacking the alternative hypothesis, leading to a decrease in support for the focal hypothesis. However, another explanation stems from a conversational or Gricean norms perspective (Grice, 1975): subjects might be assuming (quite naturally) that we would only ask about the target territory if it was important for some reason. Indeed, in some of their original work on support theory, Tversky and Koehler (1994) wrote, "Subjects, therefore, might treat the fact that the hypothesis has been brought to their attention as information about its probability" (p. 553), suggesting that simply asking about a particular territory may make it seem more important. Tversky and Koehler go on to demonstrate evidence for predictions from support theory relating to subadditivity even when avoiding experimental suggestion. Thus, it appears that the predictive power of support theory remains, even when

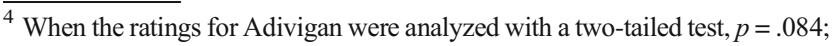
note that the two-tailed non-parametric test was still statistically significant.
}

accounting for conversational norms. Experiment 3, however, addressed this concern by providing subjects with information about every territory in all conditions and emphasizing that subjects were evaluating a territory selected at random.

\section{Experiment 3}

Experiment 3 had two goals. The first was to provide all subjects with information about the territories in Oloram before making a rating. This - along with emphasizing that the focal territory was selected at random - reduced the impact of conversational norms. The other goal was to include a true "packed" condition. To that end, subjects in the "unpacked" condition rated all of the territories at once (i.e., with no focal territory), whereas subjects in the "packed" condition rated a target territory and provided a rating for the "other" territories as a unit. Based on support theory, we predicted that (a) subjects would provide a higher estimate of historical contribution for the target territory in the packed condition, and (b) summed estimates of the non-target territories would be higher in the unpacked condition.

\section{Method}

Subjects We recruited 206 Amazon Turk Workers (116 males, 89 females, one other; age: $M=35.65$ years, $S E=0.75)$. We excluded two subjects who did not speak English fluently from our analysis. Additionally, we preregistered two additional exclusion criteria, which removed eight subjects from our analyses: seven subjects for not completing a brief compliance check at the start of the study (Zhou \& Fishbach, 2016) and one subject for taking too long to answer the critical question.

Materials and procedure The procedure was similar to Experiment 2 with two changes. First, before making a rating, all subjects read descriptions of all five territories in Oloram. Subjects were then randomly assigned to the unpacked $(n=$ $100)$ or the packed condition $(n=106)$. The unpacked condition was identical to the unpacked condition in Experiment 2: subjects saw the names and descriptions of the territories displayed in a random order on a single screen and were asked to rate how much each of the territories had contributed to the history of Oloram. Second, subjects in the novel packed condition were told that they had been randomly assigned to focus on Adivigan and then rated both Adivigan's historical contribution and "the four other territories in Oloram." The rest of the procedure was the same.

\section{Results}

Table 1 shows the estimated ratings of historical contributions for the packed and unpacked conditions. As expected, the 
ratings for Advigan were higher in the packed condition $(M=$ $32 \% ; \mathrm{Mdn}=25 \% ; 95 \% \mathrm{CI}=[28 \%, 36 \%])$ than the unpacked condition $(M=19 \% ; \mathrm{Mdn}=20 \% ; 95 \% \mathrm{CI}=[18 \%, 21 \%])$, $t(152.95)=5.78, p<.001, d=0.79$. This outcome is consistent with support theory, as unpacking the non-target hypotheses (in this case the "other" territories) reduces perceived support for the target hypothesis.

To examine whether unpacking increased perceived support for non-target hypotheses, we compared the "other" ratings from the packed condition with the sum of the ratings for the territories other than Adivigan (Brodiyan, New Ceyer, Lanemi, and Rutroka) from the unpacked condition. As expected, we found that ratings for the "other" territories was lower in the packed condition $(M=59.04 \% ; \mathrm{Mdn}=70 \% ; 95 \%$ $\mathrm{CI}=[53.85 \%, 64.22 \%])$ than in the unpacked condition $(M=$ $78.43 \% ; \mathrm{Mdn}=80 \% ; 95 \% \mathrm{CI}=[73.62 \%, 83.24 \%], t(203.59)$ $=5.44, p<.001, d=0.76$. The subadditivity here is consistent with the support theory. Non-parametric analyses revealed similar conclusions about Adivigan, $T=3366.5, p<.001$, and the "other" territories, $T=2969, p<.001$.

\section{Discussion}

The results of Experiment 3 were consistent with support theory. Subjects displayed an unpacking effect, where evaluating territories individually led to higher ratings than rating the territories as a group (demonstrating subadditivity). Furthermore, unpacking the other territories reduced support for the target territory. Critically, this pattern held even when providing subjects with more information about all of the territories and reducing the impact of conversational norms.

One relevant aspect of support theory here is anchoring and adjustment. People may anchor on their initial impression of the territory's importance and then fail to adequately adjust to

Table 1 Ratings of historical contribution for the different territories in the packed and unpacked conditions in Experiment 3

\begin{tabular}{|c|c|c|c|c|c|c|}
\hline & \multicolumn{3}{|c|}{ Packed } & \multicolumn{3}{|c|}{ Unpacked } \\
\hline & Mean & Median & $95 \% \mathrm{CI}$ & Mean & Median & $95 \% \mathrm{CI}$ \\
\hline Adivigan & $32 \%$ & $25 \%$ & $28 \%, 36 \%$ & $19 \%$ & $20 \%$ & $18 \%, 21 \%$ \\
\hline \multicolumn{7}{|l|}{ Other } \\
\hline Brodiyan & & & & $17 \%$ & $20 \%$ & $15 \%, 19 \%$ \\
\hline New Ceyer & & & & $23 \%$ & $20 \%$ & $19 \%, 24 \%$ \\
\hline Lanemi & & & & $20 \%$ & $20 \%$ & $18 \%, 22 \%$ \\
\hline Rutroka & & & & $20 \%$ & $20 \%$ & $18 \%, 22 \%$ \\
\hline Other total & $59 \%$ & $70 \%$ & $54 \%, 64 \%$ & $78 \%$ & $80 \%$ & $74 \%, 83 \%$ \\
\hline
\end{tabular}

Note. Participants in the packed condition rated the importance Adivigan and the other four territories combined ("Other total"). Participants in the unpacked condition rated the importance of Adivigan and the other four territories individually (summed to create "Other total") the mathematically "correct" response (Rottenstreich \& Tversky, 1997; Tversky \& Kahneman, 1974). Alternatively, people may anchor on the mathematically correct response and then incorrectly adjust based on their impression of the territory's importance. This might explain the curious finding that in both conditions the combined total of all ratings was less than $100 \%$ (91\% in the packed condition and $97 \%$ in the unpacked condition). Future work could differentiate between these two categories of anchoring and adjustment.

\section{Experiment 4}

Experiments 1-3 showed subjects based their ratings largely on the focal hypothesis and that increasing attention to the alternative hypotheses lowers support for the target. These effects are well explained by the implicit subadditivity aspect of support theory, which is thought to be driven by the availability heuristic: seeing category exemplars makes that category seem more likely (Tversky \& Kahneman, 1973). In Experiments 4 and 5 we focused on availability as an explanatory mechanism.

The original conception of the availability heuristic was that judgments can be influenced by the fluency with which information comes to mind (Tversky \& Kahneman, 1973). However, availability is often interpreted in a broader fashion, where judgments are influenced by the amount of content that comes to mind rather than the fluency with which it was retrieved (M. Ross \& Sicoly, 1979; Thompson \& Kelley, 1981). Thus, in Experiment 4 subjects read descriptions of one territory that varied in their level of detail. Support theory predicts that subjects should overclaim responsibility in all conditions, and based on the aforementioned content view of the availability heuristic, we predicted that subjects who read a more detailed description of Adivigan would overclaim more than subjects who read a less detailed description.

\section{Method}

Subjects We recruited 301 people from Amazon Mechanical Turk (166 male and 135 female; age: $M=35.55$ years, $S E=$ 0.71). No subjects met our aforementioned exclusion criteria so we analyzed all of our data.

Materials and procedure The basic materials and procedure were similar to the 20-Territory condition from Experiment 1. Subjects were randomly assigned to the minimal content $(n=$ $104)$, content $(n=100)$, or detailed content $(n=97)$ condition. $^{5}$

\footnotetext{
${ }^{5}$ Our preregistration specified two levels of detail about Adivigan: content and minimal content. After collecting pilot data, we added an additional condition that was in between the other two. We renamed the previous content condition as "detailed content" and called this new condition the "content" condition.
} 
The minimal content (i.e., control) condition provided minimal information about Adivigan:

"Oloram is a country that has existed for over a hundred years. Within Oloram there are 20 territories, each of which has its own government that works in conjunction with the national government. Adivigan is one of the 20 territories in Oloram.

In terms of percentage, what do you think was Adivigan's contribution to the history of Oloram? In other words, how responsible was Adivigan for the historical developments in Oloram? Keep in mind that there are 20 territories and that the total contribution for all territories has to equal $100 \%$."

In the content condition, subjects saw the same information from the minimal content condition, but with an additional paragraph in the middle of the description:

"It [Adivigan] is a coastal area in the Northern region. Adivigan's population is split between several large cities and many rural communities. There are many industries, the most prominent being shipping, trade, and education. A popular tourist attraction is the Moadia forest, which is home to a variety of flowers, trees, and native wildlife."

Finally, subjects in the detailed content condition read a description where the extra paragraph provided detailed information about Adivigan:

"It [Adivigan] is a coastal area in the Northern region. It was founded early in the history of Oloram as a shipping port, and trade continues to be a major industry. More recently, Adivigan has become a financial center, with over 30 national and international financial institutions. A popular tourist attraction is the Moadia forest, which is home to several rare tree species."

The rest of the procedure was identical to Experiment 1.

\section{Results}

Figure 4 shows the average estimated contribution of Adivigan for each condition. One-sample $t$-tests comparing the average response in each condition to 5\% (assuming equal contributions from all territories) revealed that subjects in all conditions overclaimed responsibility: minimal content $(M=$ $14 \% ; M d n=5 \% ; 95 \% \mathrm{CI}=[10 \%, 18 \%], t(103)=4.72, p$ $<.001)$, content $(M=26 \% ; \mathrm{Mdn}=20 \% ; 95 \% \mathrm{CI}=[22 \%$, $31 \%], t(99)=9.24, p<.001)$, and detailed content $(M=$ $36 \% ; \operatorname{Mdn}=30 \% ; 95 \% \mathrm{CI}=[31 \%, 41 \%], t(96)=12.24, p$
$<.001)$. This supported our first hypothesis, that people would overclaim responsibility.

More importantly, the description of Adivigan influenced ratings of historical contributions, $F(2,298)=23.84, p<.001$. Subjects in the minimal content condition gave lower estimates compared to subjects in the content condition, $t(195.06)=4.02, p<.001, d=0.56$, who in turn provided lower estimates than subjects in the detailed content condition, $t(192.36)=2.89, p=.002, d=0.41$. Non-parametric analyses yielded a similar conclusion: minimal content vs. content, $T=3006, p<.001$ and content vs. detailed content, $T=3513.5, p<.001$. Taken together these results indicate that reading more detailed information about Adivigan led to higher estimates of its historical contributions to Oloram.

Finally, as an exploratory analysis we examined the number of subjects who provided an additive response (i.e., the number of subjects who provided a response of 5\%). Notably, this value changed across conditions: $57 \%$ of subjects in the minimal content condition, $23 \%$ of subjects in the content condition, and $5 \%$ of subjects in the detailed content condition. This suggests that as people hear more details about Adivigan they are less likely to use a mathematical approach.

\section{Discussion}

As predicted, subjects overclaimed responsibility for Adivigan's contributions to Oloram (compared to the assumption that all territories contributed equally). This overclaiming increased as subjects read more detailed descriptions of Adivigan. This outcome supports the content view of the

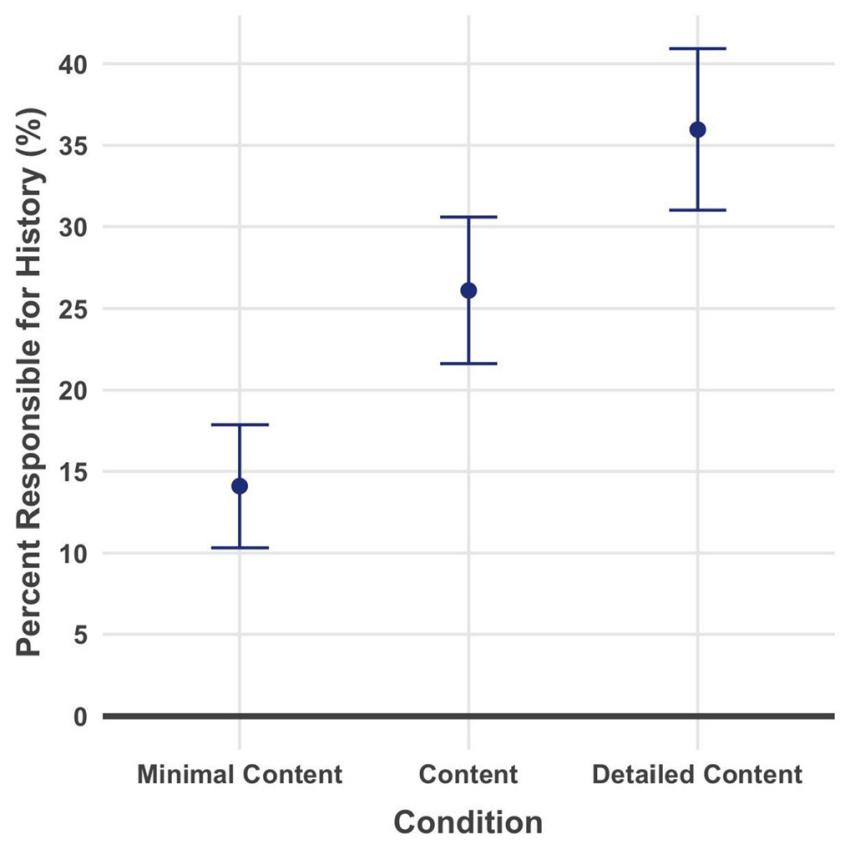

Fig. 4 Percentage estimate of how much Adivigan has contributed to the history of Oloram as a function of content provided about Adivigan in Experiment 4. Error bars represent $95 \%$ confidence intervals 
availability heuristic in support theory; more information is available when a proposition is unpacked, and consequentially subjects overestimate the importance of the proposition. ${ }^{6}$ However, the availability heuristic also suggests that the same content may have a different effect if it is more or less fluently retrievable. Experiment 5 investigated specifically whether fluency affects overclaiming of responsibility.

\section{Experiment 5}

To untangle the content and fluency views of the availability heuristic, Schwarz et al. (1991) developed a novel paradigm: subjects given a difficult task (generating 12 instances of being assertive) rated themselves as being less assertive than subjects given an easy task (generating six instances of being assertive). Although subjects were likely equally assertive across conditions, subjects interpreted the difficulty of the generation task as an indicator of their assertiveness. We applied this methodology to our paradigm by having subjects generate reasons a territory made an important contribution to Oloram.

\section{Method}

Subjects We recruited 365 MTurkers (196 males, 168 females, one other; age: $M=36.59$ years, $S E=0.59$ ). Because this experiment was testing the effects of a fluency manipulation, we preregistered several additional exclusion criteria, based on a pilot study that was identical to Experiment 5 (reported in the Supplemental Online Materials). ${ }^{7}$ We excluded data from 58 subjects for: not providing two reasonable responses in the generate 2 condition, ${ }^{8}$ not providing six reasonable responses in the generate 8 condition, taking longer than 5 or 9 min to generate items (in the generate 2 and generate 8 conditions, respectively), or taking longer than $3 \mathrm{~min}$ to answer the critical questions. Additionally, we omitted data from four subjects with duplicate Mechanical Turk ID's (suggesting that the same subject completed the study twice).

\footnotetext{
${ }^{6}$ An alternative interpretation is that subjects may use the representativeness heuristic (Tversky \& Kahneman, 1973) and simply judge a longer description to indicate a more important territory. Although this would explain why the "minimal content" condition yielded the smallest claims of responsibility, it would fail to explain the difference between the "content" and "detailed content" conditions, which were the same length.

${ }^{7}$ A second version of this experiment is reported in our SOM. Briefly, we also found a null effect, but did not report the study in the main manuscript because we excluded more data than expected.

${ }^{8}$ An example of an unreasonable response would be leaving the response field blank, or reporting something completely unrelated to the task (e.g., writing "nice" as their entire response).
}

Materials and procedure The procedure was similar to the earlier studies. Subjects read about the five territories in a randomized order before being told that they had been randomly assigned to consider Adivigan specifically. Subjects were then randomly assigned to one of three groups. One group generated two ways that Adivigan contributed to the history of Oloram $(n=117)$, another group generated eight ways $(n=103)$, and a control group did not have to generate historical contributions $(n=145)$. In the generation conditions, subjects were specifically told to either recall specific facts about the target territory or theorize about how some aspects of the territory might affect Oloram. Subjects then rated how much Adivigan had contributed to the history of Oloram. Finally, as a manipulation check, subjects in the generate 2 and generate 8 conditions reported the difficulty in generating their responses on a 1-100 scale.

\section{Results}

Because we had two competing hypotheses, we used twotailed tests for all analyses in Experiment 5. Our manipulation check revealed that subjects found it more difficult to generate eight items $(M=57 ; \mathrm{Mdn}=62 ; 95 \% \mathrm{CI}=[52 \%, 62 \%])$ than to generate two items $(M=44 ; \mathrm{Mdn}=49 ; 95 \% \mathrm{CI}=[40 \%$, $48 \%]), t(202.45)=4.12, p<.001, d=0.56$.

Critically, a one-way between subjects ANOVA revealed no significant difference in subject's estimates of Adivigan's contribution regardless of if they were in the control group ( $M$ $=42 \% ; \mathrm{Mdn}=35 \% ; 95 \% \mathrm{CI}=[38 \%, 45 \%])$, the generate 2 group $(M=39 \%$; $\mathrm{Mdn}=35 \% ; 95 \%$ CI $[36 \%, 43 \%])$, or the generate 8 group $(M=45 \% ; \mathrm{Mdn}=40 \% ; 95 \% \mathrm{CI}=[41 \%$, $49 \%]), F(2,362)=1.81, p=.165$. While it is difficult to interpret null effects, this outcome suggests that retrieval fluency did not strongly affect people's ratings. Examining the means, however, indicates that the generate 8 condition led to higher estimations than the generate 2 or control conditions, suggesting that generating more items may have increased perceived support for the target territory. Finally, we ran a non-parametric Kruskal Wallis rank sum test, which also failed to find a significant effect, $\chi^{2}(2)=4.34, p=.144$.

\section{Discussion}

Experiment 5 tested whether fluency influenced collective overclaiming. Given the null results, this study is difficult to interpret. However, one exploratory analysis (reported in our Supplemental Online Materials), including all subjects and using non-parametric statistics, found that subjects in the generate 8 condition provided significantly higher ratings than subjects in the generate 2 condition $(p=.016)$, albeit with a small effect size $(d=0.26)$. Regardless, our results are consistent with work showing that people are more likely to rely on their experiential fluency when they have expertise in the 
relevant domain (e.g., one's own history of being assertive; Schwarz et al., 1991). Without such expertise - as is often the case in collective contexts - people are more likely to rely on the amount of content retrieved from memory than on fluency (Schwarz and Vaughn, 2002). Together with the results of Experiment 4, which found strong support for the content view of availability, we conclude that content is more influential than fluency when examining the role of availability in support theory predictions of collective overclaiming.

\section{General discussion}

In the current project we used a novel paradigm to examine cognitive mechanisms that underlie collective overclaiming. We focused on the role of support theory and availability (and avoided ego-protection mechanisms) by having people evaluate fictitious territories. We showed that overclaiming increased as the number of territories increased (Experiment 1), that rating a territory in isolation led to higher ratings than rating it alongside other territories (Experiments 2 and 3), that providing more content about a territory led to larger claims of responsibility (Experiment 4), and that increasing the fluency of information retrieved about a territory had no effect on or even reduced overclaiming (Experiment 5). These experiments help us understand collective overclaiming in several ways.

First, overclaiming occurred in our novel paradigm without self-serving biases. This is important because findings that people overclaim for negative outcomes may still be based on ego-protection. In the current paradigm, however, it is unlikely that subject would strongly identify with Adivigan (or any fictitious territory) after reading a cursory description. Thus, overclaiming effects must be driven in part by cognitive factors, consistent with prior work (M. Ross \& Sicoly, 1979; Savitsky et al., 2005; Schroeder et al., 2016).

Second, the current study affirms the explanatory power of support theory and the role of the availability heuristic in predictions of overclaiming. People neglected to consider non-focal territories across several studies, demonstrating the robust predictive power of support theory. Moreover, while a more detailed description of a territory led to more overclaiming, increasing the fluency of recalling information about a territory did not. To our knowledge, no studies have manipulated the fluency of retrieval of contributions before making an overclaiming judgment. The role of fluency, as suggested by the availability heuristic, appeared less important for support theory predictions about overclaiming, perhaps because people were evaluating an unfamiliar domain.

Third, this understanding of support theory sheds light on how to address overclaiming. Unpacking alternatives appears to be crucial; simply reading cursory information about other alternatives, or evaluating them along with the focal proposition, successfully mitigated overestimations. By examining the role of availability in support theory, the current research offers a hopeful note. In the USA, American history will always be more fluently retrievable than the history of other nations. However, we find that available content - rather than fluency - reduces overclaiming. This suggests that simply knowing the histories of other countries may mitigate inflated perceptions of one's own country, even if these histories are harder to recall.

Finally, it is important to note that the current studies model collective overclaiming. Rather than rating individuals' contributions to a group, participants in the current studies rated the contribution of a group to a larger whole. We aimed to demonstrate that similar processes are involved with overclaiming for individuals as well as groups. Our results show that support theory and the content view of the availability heuristic also play a role in collective overclaiming, but that fluency may be less important, as people are often less familiar with group contributions. We note, however, that our desire to mitigate ego-protection effects complicates this conclusion. Such mechanisms (e.g., group identification) play a crucial role in collective overclaiming, as people endeavor to not only protect themselves but also their groups (Churchill, Yamashiro, \& Roediger, 2019; Zaromb et al., 2018). Future research should continue to explore whether collective overclaiming functions similarly to individual overclaiming.

There are some limitations to the current research. As noted earlier, people may pick up on suggestions in the design of the study - if Adivigan weren't that important, then why would we be asking about it? While this may be the case, support theory accounts for this effect; studies show that even without experimental suggestion people display subadditivity and base their judgments on the focal hypothesis (Tversky \& Koehler, 1994). Moreover, overclaiming still occurred when we provided information about all of the territories and informed participants that the focal territory was selected at random (Experiment 3), suggesting that conversational norms alone do not account for overclaiming.

A second limitation is that subject numeracy may affect responses. Across all experiments different conditions varied in the likelihood of treating the question like a math problem, with subjects generally providing mathematically "correct" answers when the math was easier, when they were evaluating all territories at once, or they had less information about the territory in question. As quantitatively literate people are more likely to respect additivity, and people can be primed to respect additivity, numeracy and general quantitative reasoning may be important in understanding overclaiming (Riege \& Teigen, 2013). However, overclaiming still occurred when the number of territories was held constant; numeracy alone cannot be responsible for our findings.

Similarly, we note that our critical question ended with a reminder that the total contribution of all territories should 
equal $100 \%$. Sticking to additivity is not natural for most subjects, so it is likely that some tried to follow this suggestion whereas others did not (or ignored the suggestion entirely), and that the average responses we saw were a combination of both types of responses. However, past research in our lab (Putnam et al. 2018) has shown that this small reminder significantly lowers subject responses, indicating that the means (and overclaiming) seen in our data are likely underestimates.

One last limitation is that our paradigm is unrealistic due to its fictitious nature, making it hard to draw straight lines from our research into the real world. In the real world, people will always have more detailed information about their home territory, which if anything should increase overclaiming. Past research in our lab (Putnam et al., 2018) clearly shows powerful overclaiming effects; critically, both lay people and researchers assume that motivated factors are the primary mechanism behind these effects. Our main goal with this project was to show that some of this overclaiming is due to cognitive rather than motivated factors. Future work can explore these concepts in more realistic scenarios.

In sum, the current studies are revealing in showing that overclaiming occurs without ego-protection. Instead, cognitive biases, such as support theory and the availability of content, can explain these patterns of overclaiming. This work has theoretical weight for the study of collective overclaiming as well as practical impact regarding nationalism and other phenomena.

Acknowledgements We thank Magdalena Abel, Jeremy Yamashiro, and Kurt DeSoto for helpful comments on the manuscript. This research was supported by Carleton College and Furman University.

Open Practices Statement Experiments 1, 3, 4, and 5 were preregistered on the Open Science Framework. The data and materials from all experiments are available (along with the preregistrations) at the link listed above.

\section{Appendix}

Full descriptions of the five territories in Experiments 2 and 3 are:

Rutroka is one of five territories in Oloram. It is located in the southern region of the country, and bounded by a river in the north. Rutroka's geography consists of low mountains and prairies, and people have settled throughout this territory. The capital of Oloram is located in this territory, which makes government and tourism prominent. The economy also depends on agriculture and mining. Because it is located in the south, earthquakes are a concern for the inhabitants of Rutroka.

New Ceyer is one of five territories in Oloram. It is located in the eastern region of the country, which means there is often heavy rainfall. New Ceyer has a long coastline and flat, fertile land. Because of its geography, people live in a number of small towns throughout this territory. Industries in New Ceyer include fishing, food processing, and defense. Its rainfall and proximity to the coast make flooding a concern for the inhabitants of New Ceyer.

Brodiyan is one of five territories in Oloram and is located in the western region of the country. Brodiyan has a diverse geography, with numerous lakes, large forests, and valleys. People have settled in both large and small groups, often in the forested areas. Brodiyan's economy is supported through manufacturing, petroleum, and transportation. Because it is located in the west, extreme temperatures are a concern for the inhabitants of Brodiyan. The current president of Oloram grew up in this territory.

Lanemi is one of five territories in Oloram. It is surrounded by small hills, and is located in the central region of the country. Lanemi has vast desertous regions in the southeast, so people tend to cluster in the western region of the territory where there are grasslands and a more temperate climate. This region is home to a newly erected statue memorializing those who fought in the Battle of 1897. There are many industries in Lanemi, the most prominent being natural gas, technology, and education. Because it is centrally located with a large dry region, droughts are a concern for the inhabitants of Lanemi.

Adivigan is one of five territories in Oloram. It is a coastal area in the northern region. Adivigan's population is split between several large cities and many rural communities. There are many industries, the most prominent being shipping, trade, and education. A popular tourist attraction is the Moadia forest, which is home to a variety of flowers, trees, and native wildlife.

\section{References}

Brenner, L. A., Koehler, D. J., \& Rottenstreich, Y. (2002). Remarks on support theory: Recent advances and future directions. In T. Gilovich, D. Griffin, \& D. Kahneman (Eds.), Heuristics and Biases (pp. 489-509).

Caruso, E. M., Epley, N., \& Bazerman, M. H. (2006). The costs and benefits of undoing egocentric responsibility assessments in groups. Journal of Personality and Social Psychology, 91, 857-871. https:// doi.org/10.1037/0022-3514.91.5.857

Churchill, L., Yamashiro, J. K., \& Roediger, H. L. (2019). Moralized memory: binding values predict inflated estimates of the group's historical influence. Memory, 15, 1-11. https://doi.org/10.1080/ 09658211.2019 .1623261

Gilovich, T., Kruger, J., \& Savitsky, K. (1999). Everyday egocentrism and everyday interpersonal problems. In R. M. Kowalski \& M. R. Leary (Eds.), The social psychology of emotional and behavioral problems: Interfaces of social and clinical psychology (pp. 69-95). Washington, DC, US: American Psychological Association. 
Grice, H. P. (1975). "Logic and Conversation". Logic and Conversation. Leiden, The Netherlands: Brill. https://doi.org/10.1163/ 9789004368811003

Klar, Y. (2002). Way beyond compare: Nonselective superiority and inferiority biases in judging randomly assigned group members relative to their peers. Journal of Experimental Social Psychology, 38, 331-351.

Kruger, J., \& Gilovich, T. (1999). " Naive cynicism" in everyday theories of responsibility assessment: On biased assumptions of bias. Journal of Personality and Social Psychology, 76, 743.

Leary, M. R., \& Forsyth, D. R. (1987). Attributions of responsibility for collective endeavors. In C. Hendrick (Ed.), Review of personality and social psychology, Vol. 8. Group processes (pp. 167-188). Thousand Oaks, CA, US: Sage Publications, Inc.

McConnell, A. R., Sherman, S. J., \& Hamilton, D. L. (1994). On-line and memory-based aspects of individual and group target judgments. Journal of Personality and Social Psychology, 67, 173-185.

Putnam, A. L., Ross, M. Q., Soter, L. K., and Roediger, H. L., III. (2018). State narcissism in collective remembering: Residents exaggerate the role of their state in appraising U.S. history. Psychological Science, 29, 1414-1422.

Riege, A. H., \& Teigen, K. H. (2013). Additivity neglect in probability estimates: Effects of numeracy and response format. Organizational Behavior and Human Decision Processes, 121, 41-52. https://doi. org/10.1016/j.obhdp.2012.11.004

Roediger, H. L., Abel, M., Umanath, S., Shaffer, R. A., Fairfield, B., Takahashi, M., \& Wertsch, J. V. (2019). Competing national memories of World War II. Proceedings of the National Academy of Sciences, 116, 16678-16686. https://doi.org/10.1073/pnas. 1907992116

Ross, M., \& Sicoly, F. (1979). Egocentric biases in availability and attribution. Journal of Personality and Social Psychology, 37, 322-336. https://doi.org/10.1037/0022-3514.37.3.322

Rottenstreich, Y., \& Tversky, A. (1997). Unpacking, repacking, and anchoring: Advances in support theory. Psychological Review, 104(2), 406-415. https://doi.org/10.1037/0033-295X.104.2.406

Savitsky, K., Van Boven, L., Epley, N., \& Wight, W. M. (2005). The unpacking effect in allocations of responsibility for group tasks. Journal of Experimental Social Psychology, 41, 447-457.

Schroeder, J., Caruso, E. M., \& Epley, N. (2016). Many hands make overlooked work: Overclaiming of responsibility increases with group size. Journal of Experimental Psychology: Applied, 22, 238-246. https://doi.org/10.1037/xap0000080.supp

Schwarz, N., \& Vaughn, L. A. (2002). The availability heuristic revisited: Ease of recall and content of recall as distinct sources of information. In T. Gilovich, D. Griffin, \& D. Kahneman (Eds.), Heuristics and Biases (pp. 103-119).

Schwarz, N., Bless, H., Strack, F., Klumpp, G., Rittenauer-Schatka, H., \& Simons, A. (1991). Ease of retrieval as information: Another look at the availability heuristic. Journal of Personality and Social Psychology, 61, 195-202.

Taylor, S. E., \& Brown, J. D. (1988). Illusion and well-being: A social psychological perspective on mental health. Psychological Bulletin, 103, 193-210. https://doi.org/10.1037/0033-2909.103.2.193

Thompson, S. C., \& Kelley, H. H. (1981). Judgments of responsibility for activities in close relationships. Interpersonal Relations and Group Processes, 41, 469-477. https://doi.org/10.2307/281263

Tversky, A., \& Kahneman, D. (1973). Availability: A heuristic for judging frequency and probability. Cognitive Psychology, 5, 207-232.

Tversky, A., \& Kahneman, D. (1974) Judgment under Uncertainty: Heuristics and Biases. Science 185 (4157):1124-1131

Tversky, A., \& Koehler, D. J. (1994). Support theory: A nonextensional representation of subjective probability. Psychological Review, 101, $547-567$

Windschitl, P. D., Kruger, J., \& Simms, E. N. (2003). The influence of egocentrism and focalism on people's optimism in competitions: When what affects us equally affects me more. Journal of Personality and Social Psychology, 85, 389-408. https://doi.org/ 10.1037/0022-3514.85.3.389

Zaromb, F. M., Liu, J. H., Paez, D., Hanke, K., Putnam, A. L., \& Roediger, H. L. (2018). We made history: Citizens of 35 countries overestimate their nation's role in world history. Journal of Applied Research in Memory and Cognition, 7, 521-528. https://doi.org/10. 1016/j.jarmac.2018.05.006

Zhou, H., \& Fishbach, A. (2016). The pitfall of experimenting on the web: How unattended selective attrition leads to surprising (yet false) research conclusions. Journal of Personality and Social Psychology, 111, 493-504. https://doi.org/10.1037/pspa0000056

Publisher's note Springer Nature remains neutral with regard to jurisdictional claims in published maps and institutional affiliations. 